\title{
Clinical research Edgara $\mathrm{H}$. Scheina - badanie kultury organizacyjnej między metodyką psychologii, socjologii i antropologii
}

\author{
Agnieszka Jeran \\ UAM
}

\author{
Anita Basińska \\ Uniwersytet SWPS
}

DOI: http://dx.doi.org/10.18778/1733-8069.16.3.07

\section{Słowa kluczowe: badania organizacji, clinical research, kultura organizacyjna, E. H. Schein}

\begin{abstract}
Abstrakt: Jedną z powszechnie przywoływanych w literaturze koncepcji kultury organizacyjnej jest ujęcie E. Scheina, który ujmuje kulturę organizacyjną funkcjonalnie, interpretatywnie i dynamicznie, wskazując na jej złożoność i wielopoziomowość. Schein przedstawił także autorski sposób badania kultury organizacyjnej, który nazwał clinical research (CR). W tekście autorki omówiły podejście CR i wskazały zakres wspólnych rozwiązań metodologicznych między CR a diagnozą psychologiczną, interwencją socjologiczną oraz etnografią. CR z diagnozą psychologiczną łączy poszukiwanie przez organizację wsparcia (u badacza) i wymaganie zaangażowania członków organizacji w badanie. Podobnie jak interwencja socjologiczna A. Touraina CR posługuje się własnymi pojęciami badanych, opiera się na ich refleksyjności i akceptacji konkluzji badania. Analogicznie do etnografii CR każdą organizację traktuje jako odrębny przypadek, zaś badacza uczula na stałe budowanie relacji z badanymi. Wykorzystanie CR w badaniach kultury organizacyjnej jest zatem unikalnym w procedurach badań organizacyjnych przykładem integracji metod badawczych nauk społecznych i humanistycznych.
\end{abstract}

Agnieszka Jeran, dr hab., socjolog, adiunkt na Wydziale Socjologii Uniwersytetu im. Adama Mickiewicza w Poznaniu. Naukowo interesuje się ilościowymi metodami badań i metodami ich statystycznej analizy, tranzycją szkoła-praca i zagadnieniami społeczności lokalnych. Uczestniczyła w różnorodnych projektach badawczych, między innymi dotyczących migrantów z Polski i ich uczestnictwa w kulturze, rynku pracy ar- tystów i twórców czy kompetencji psychoedukacyjnych uczniów.
Adres kontaktowy:
Wydział Socjologii
Uniwersytet im. Adama Mickiewicza w Poznaniu ul. Szamarzewskiego 89c, 60-568 Poznań
e-mail: jeran@amu.edu.pl 
Anita Basińska, dr, socjolog, adiunkt, kierownik Katedry Projektowania Uniwersytetu SWPS (School of Form). Naukowo interesuje się przede wszystkim praktycznym zastosowaniem socjologii - badaniami społecznymi, metodologią prowadzenia badań, wykorzystaniem wiedzy socjologicznej w realnym życiu. Uczestniczyła w licznych projektach badawczych, w tym dotyczących designu w domu dziecka, kompetencji dzieci, kreatywności dzieci, funkcjonowania przedsiębiorstw (kultury organizacyjnej, działalności B+R), wolontariatu.

\section{Adres kontaktowy:}

SWPS

Uniwersytet Humanistycznospołeczny

Wydział Psychologii i Prawa w Poznaniu

Katedra Projektowania

(School of Form)

ul. gen. T. Kutrzeby 10

61-719 Poznań

e-mail: abasinska@sof.edu.pl

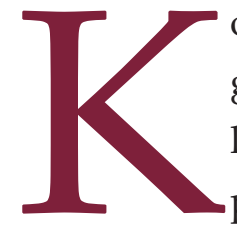

oncepcja kultury organizacyjnej Edgara H. Scheina jest jedną z najpopularniejszych koncepcji cytowanych dygmatu funkcjonalistycznego, przede wszystkim dlatego, że kultura w tym ujęciu pełni określone funkcje w organizacji i podlega świadomym interwencjom, a zatem można ją zmienić. Zaczynając od krótkiej rekapitulacji obecności koncepcji Scheina w podręcznikach oraz od omówienia jej założeń, w tekście przedstawiamy przede wszystkim zaproponowane przez Scheina podejście do badania kultury organizacyjnej - clinical research (CR) - silnie zakorzenione $\mathrm{w}$ nurcie interpretatywnym i uwzględniające dynamiczny charakter kultury. Kontekst przedstawienia i analizy CR stanowią inne - wybrane spośród powszechnie wykorzystywanych - procedury badania kultury organizacyjnej, często odwołujące się nie tylko do odmiennych założeń metodologicznych, ale i do odmiennego rozumienia kultury. Cel artykułu to prezentacja podejścia CR jako sposobu badania kultury organizacyjnej, który w swych założeniach podobny jest do pewnych aspektów wybranych procedur psychologicznych, socjologicznych i antropologicznych, takich jak diagnoza psychologiczna, interwencja socjologiczna i etnografia. Podejścia CR nie da się jednoznacznie zaklasyfikować do żadnej z dyscyplin, które przywołujemy, i tym samym postawić znaku równości między chociażby CR i diagnozą psychologiczną czy CR i etnografią. Celem tekstu jest jednak wskazanie pewnych wspólnych cech tych podejść badawczych.

\section{Kultura w ujęciu Edgara H. Scheina}

\section{Przegląd podręczników - powszechna obecność koncepcji Scheina}

W sierpniu 2019 roku dokonano w bibliotece Uniwersytetu Ekonomicznego w Poznaniu przeglądu podręczników zaklasyfikowanych jako poświęcone kulturze przedsiębiorstwa i zachowaniom w organizacji, uzupełnionych o książki zawierające w tytule pojęcie „kultura organizacyjna”. Wprowadzono ograniczenie dotyczące wydania książki 
nie wcześniej niż w 2009 roku. Miało to pozwolić na oszacowanie i zilustrowanie powszechności przywoływania koncepcji Scheina w odniesieniu do kultury organizacyjnej $\mathrm{w}$ najnowszej literaturze propedeutycznej nauk o zarządzaniu. Przegląd dziesięciu podręczników pozwala stwierdzić, że w większości z nich albo obecna była definicja kultury według Scheina (Sikorski 2009; Czerska, Szpitter 2010; Kożusznik 2014; Okręglicka 2019), albo omówiony został jego model (Srokowski 2011; Czerska 2012; Kostera, Śliwa 2012; Robbins, Judge 2012). Tylko w dwóch przeanalizowanych podręcznikach (Kmiotek, Piecuch 2012; Sułkowski 2014) nie znalazły się odniesienia do koncepcji kultury Scheina. Komentarze autorów wskazują na znaczenie tego ujęcia, na przykład Sikorski uznaje, że ta definicja należy do najbardziej znanych definicji kultury organizacyjnej (2009: 155), zaś Srokowski określa Scheina jako „wybitnego badacza organizacji” (2011: 28). Jednocześnie powszechność przywoływania definicji i treści kultury w ujęciu Scheina nie przekłada się na przytoczenie jego podejścia do badania kultury organizacyjnej i diagnozowania problemów organizacji jako takich, ani $\mathrm{w}$ treści przeanalizowanych prac, ani w ich spisach bibliograficznych nie znajdowały się prace Scheina poświęcone podejściu CR.

\section{Rekapitulacja założeń Scheina}

Po pierwsze, dla Scheina kultura organizacyjna jest jedną z kategorii kultur, w których funkcjonuje człowiek. Najszerszą kategorią kulturową są makrokultury (macrocultures), które istnieją globalnie, są to: narody, grupy etniczne i religijne, grupy zawodowe (rozumiane szeroko, np. prawnicy, inżynierowie, lekarze). Nieco węższą kategorią są właśnie kultury organizacyjne (organizational cultures), czyli kultury organizacji prywatnych lub publicznych. Jeszcze węższą kategorią są subkultury (subcultures), czyli kultury grup zawodowych funkcjonujących wewnątrz organizacji. Ostatnią, najwęższą kategorią są mikrokultury (microcultures) - mikrosystemy wewnątrz bądź na zewnątrz organizacji (np. zespół chirurgów, zespół pracowniczy) (Schein 2010: 2). Schein podkreśla, że kultura nie tylko otacza człowieka, ale przenika jego samego, jest zinternalizowana. Kultura pomaga wyjaśnić i znormalizować różne zjawiska w organizacji, na przykład zachowania niesubordynacji, brak współpracy w grupie, konflikty między członkami grupy, różnice pomiędzy zespołami pracowniczymi i sposoby dopasowania do nich metod przekazania informacji, wspólnotę wartości i celów dla określonej grupy zawodowej (Schein 2010: 9).

Po drugie, kultura organizacyjna jest dynamiczna, zmienia się poprzez funkcjonowanie $\mathrm{w}$ niej ludzi, stale się odtwarza. Jednocześnie kultura gwarantuje stabilizację i niezmienność w takim znaczeniu, że określa, jak członkowie organizacji powinni postrzegać, czuć i działać w organizacji. Poza tym członkowie organizacji podlegają kulturze przymusowo (Schein 2010: 3).

Po trzecie, Schein jako zwolennik podejścia charakterystycznego dla nauk o zarządzaniu (culture management) uważa, że kulturą można zarządzać, zmieniać ją w drodze decyzji kierownictwa. Management możemy rozumieć nie tylko bezpośrednio jako zarządzanie kulturą, ale także jako manipulowanie kultura, wykorzystywanie kultury do realizacji pewnych celów, selektywne propagowanie niektórych jej elementów. Przy czym Schein wielokrotnie podkreśla, że zmiany te mają pomóc organizacji (helpful changes), usprawnić jej funkcjonowanie, poprawić relacje między pracownikami i tak dalej (Schein 2010: 186). 
Schein wskazuje, że kultura jest kreowana, utrwalana, rozwijana i manipulowana przez kierownictwo od początku istnienia grupy czy organizacji. Wraz z dojrzałością grupy kultura się stabilizuje, wspierając strukturę i podzielane znaczenia $\mathrm{w}$ grupie. Są dwie drogi zmiany kultury organizacyjnej: 1) w sytuacji, gdy kultura staje się dysfunkcjonalna, kierownictwo rozwiązuje problem poprzez wprowadzenie własnej, nowej kultury oraz 2) poprzez ewolucję. W obu sytuacjach kierownictwo decyduje, jaka kultura organizacyjna obowiązuje, inny jest tylko sposób jej wprowadzenia. Ten dynamiczny proces kreowania kultury i zarządzania jest istotą kierowania, co uświadamia, że kierowanie i kultura są dwiema stronami tego samego procesu (Schein 2010: 3).

Schein obserwował procesy przymusowej socjalizacji w badanych firmach, które doprowadzały albo do akceptacji kultury, albo do rezygnacji z pracy tych, którzy nie pasowali do organizacji (Schein 2015: 108). Sytuację, w jakiej niektóre aspekty rzeczywistości organizacyjnej są podzielane, a inne nie, i w jakiej występują różnego rodzaju konflikty, można wyjaśnić na dwa sposoby: 1) nie powstała kultura na poziomie całej organizacji - grupa nie podziela podstawowych założeń, 2) istnieje niewiele wspólnych korporacyjnych podstawowych założeń - w organizacji wyewoluowało wiele subkultur z własnymi artefaktami, wartościami i podstawowymi założeniami (taką organizację Schein postrzega jako system wielokulturowy) (Schein 2015: 109). Schein przywołuje swoje doświadczenia z prowadzenia szkoleń (treningów wrażliwości), podczas których miał możliwość obserwować, jak wspólne doświadczenie grupy stworzyło normy i specjalne znaczenia, których nowicjusz w grupie nie mógł zrozumieć, oraz jak przybycie nowego członka wymusiło ewolucję niektórych z tych norm i znaczeń (Schein 2015: 111).
Podejście Scheina jednoznacznie wskazuje więc na odgórny kierunek kształtowania kultury w organizacji - kultura stanowi nie tylko przyjmowane, ale też narzucane członkom organizacji sposoby działania i rozumienia rzeczywistości. Takie rozumienie kultury organizacyjnej wypływa wprost $z$ jej funkcjonalności i podporządkowania efektywności. Warto zauważyć, że choć to tylko jeden z kierunków kształtowania się kultury organizacyjnej, w ujęciu Scheina jest on podstawowy.

Jako składowa podporządkowana efektywności kultura organizacyjna to całość fundamentalnych założeń, które dana grupa wymyśliła, odkryła lub stworzyła, ucząc się rozwiązywania problemów adaptacyjnych do środowiska i integracji wewnętrznej (Schein 2010: 18). W ujęciu Scheina kultura jest zawsze własnością jakiejś grupy. Kultura to odzwierciedlenie wspólnej nauki, której członkowie doświadczyli, starając się przetrwać, rozwijać i jednocześnie pozostać wewnętrznie spójni. Zatem kultura składa się z komponentów, które pozwalają grupie radzić sobie z zewnętrznym otoczeniem, oraz z komponentów, które pozwalają radzić sobie wewnątrz grupy (Schein 2015: 108).

Schein skonstruował trójpoziomowy model kultury w organizacji, który opisuje elementy kluczowe dla zdefiniowania kultury i jednocześnie zapewniające jej stabilność. Kultura organizacyjna składa się zatem z trzech poziomów, mniej lub bardziej widocznych, obejmujących: artefakty, wartości i podstawowe założenia.

Najbardziej uświadamianym poziomem kultury organizacyjnej są artefakty. Są to wszystkie zjawiska, które można zobaczyć, usłyszeć, poczuć, gdy wchodzi się do nowej grupy w nieznanej kulturze. Artefakty dzielą się na: 
- artefakty językowe: mity, język, legendy,

- artefakty behawioralne: ceremonie, rytuały,

- artefakty fizyczne: sztuka, technologia, przedmioty materialne, moda, budynki.

Na kolejnym poziomie, mniej uświadamianym niż artefakty, a tym samym trudniejszym do zaobserwowania przez badacza, kierownictwo i pracowników, znajdują się podzielane wierzenia i wartości. W momencie powstania grupy ustalone zostaje, co jest dobre, a co złe, jak pracować, co będzie działać. Wartości są na wyższym poziomie świadomości niż podzielane wierzenia, ponieważ charakteryzuje je otwartość i dyskursywność (są "otwarte do dyskusji” [open to discussion]), podlegają negocjacjom, a ludzie mogą się z nimi zgadzać lub je odrzucać (Schein 2010: 26). Nie wszystkie podzielane wierzenia i wartości muszą mieć wyjaśnienie (racjonalne lub tylko racjonalizujące), nie musi więc zostać określony bezpośredni związek między nimi a osiągnięciami organizacji, chociaż zgodnie z definicją istotny jest ich funkcjonalny (nawet jeśli tylko wyobrażony) charakter.

Z kolei najgłębszy poziom kultury organizacyjnej to podstawowe założenia kulturowe, które są nieuświadomione i niewidoczne, ale uważane w organizacji za oczywiste. Ci, którzy nie chcą się im poddać, nie podzielają ich, uważani są za obcych, szaleńców i są automatycznie usuwani z grupy (Schein 2010: 23). Schein definiuje podstawowe założenia za Argyrisem i Schönem jako theories-in-use - bezwarunkowe założenia są podstawą i wyznacznikiem zachowań, które mówią członkom grupy, jak postrzegać rzeczywistość, myśleć o rzeczach i czuć je (Schein 2010: 28). Mają one charakter niepisanych, wzajemnych oczekiwań istniejących pomiędzy pracownikami i pracodawcami, mają charakter umowy, którą Schein określił mianem umowy psychologicznej (1980).
Pomiędzy tymi trzema poziomami zachodzą związki - bez sięgnięcia przynajmniej w pewnym zakresie po podstawowe założenia nie jest możliwa poprawna interpretacja artefaktów. Innymi słowy, istota kultury leży we wzorach podstawowych założeń, poprzez które dopiero można zrozumieć pozostałe poziomy. Podzielane wierzenia i wartości oraz artefakty są manifestacją kultury organizacyjnej. W analizie kultury ważne jest uświadomienie sobie, że artefakty, a częściowo także podzielane wierzenia i wartości, są łatwe do zaobserwowania, ale trudne do interpretacji.

\section{Sposoby badania kultury organizacyjnej}

Badania nad kulturą organizacyjną prowadzone są dość systematycznie od ponad 60 lat. W tym czasie badacze stosowali różne strategie poznania kultury organizacji, tworząc oryginalne narzędzia badawcze czy adaptując istniejące do warunków społeczno-kulturowo-gospodarczych, w których funkcjonowały badane przez nich organizacje. Należy podkreślić, że poznanie kultury organizacji polegało na badaniu stricte jej kultury lub badaniu kultur narodowych i przekładaniu zdefiniowanych wymiarów na typologie kultur organizacyjnych (np. Hofstede [2001], Ch. Hampden-Turner i F. Trompenaars [2002] porównywali wpływ wartości i norm kultury narodowej na zachowania pracowników).

Tradycyjny podział na ilościowe i jakościowe procedury badań społecznych można wykorzystać także $\mathrm{w}$ odniesieniu do procedur badań kultury organizacyjnej. Wśród badań o schemacie ilościowym (z takimi cechami podejścia ilościowego jak pozytywistyczne zakorzenienie, zaplanowanie, standaryzacja i obiektywizacja gromadzenia danych oraz statystyczna analiza wyników - por. Creswell 2013) można wymienić badania, w których badacze stosowali kwestionariusze ankiet lub wywiadów (w la- 
tach 70. i 80. XX w. Harrison [1972], Handy [1983], Deal i Kennedy [2000], Cameron i Quinn [2006], w latach 90. XX w. Denison [1996]). Pytania obejmowały różne aspekty kultury (np. przywództwo, zarządzanie, współpraca, konflikt, misja organizacji, wartości) i na podstawie odpowiedzi klasyfikowano kulturę danej organizacji do określonego typu/kategorii na zazwyczaj dwu- lub czterowymiarowej matrycy. Badania ilościowe pozwalają w miarę szybko scharakteryzować podstawowe aspekty kultury organizacyjnej i poprzez odniesienie do określonych wymiarów zidentyfikować kulturę badanej organizacji. $W$ ramach tych badań prowadzono i wciąż prowadzi się badania porównawcze, na przykład z wykorzystaniem kwestionariuszy Camerona i Quinna czy Hofstede. Badania porównawcze kultur w kilku krajach (Polska, Ukraina, USA, Niemcy, Rosja) prowadził także Sułkowski (2002).

Z kolei procedury jakościowe (obejmujące szereg różnych paradygmatów; ich przegląd w podejściach do badania kultury organizacyjnej przestawiają np. Kostera 1996; Sułkowski 2008) w badaniach kultur organizacyjnych to mniej lub bardziej długotrwałe badania terenowe $\mathrm{z}$ wykorzystaniem różnych metod (w zależności od problemu badawczego, możliwości i potrzeb), takich jak: obserwacje (po raz pierwszy w 1959 r. Donald. F. Roy, obserwacja uczestnicząca w fabryce), shadowing (po raz pierwszy w 1973 r. Harry Walcott w szkole [Czarniawska 2011]), wywiady mniej lub bardziej formalne (Alvesson 2002), analizy tekstów. Wymienić należy także strategie badawcze oparte na triangulacji metod i danych, jak badania etnograficzne (Czarniawska 1992; 2011; Kostera 2007) oraz studia przypadku (Konecki 1994; 2007; Kołodziej-Durnaś 2005, Kołodziej, Kołodziej-Durnaś 2012; Sułkowski 2012a). Te badania koncentrują się na zrozumieniu danej kultury organizacyjnej w jej kontekście. Najważniejszym ce- lem jest maksymalnie pogłębione badanie kultury organizacji określonego typu, na przykład badanie przedsiębiorstwa japońskiego (Konecki 1994), statku morskiego (Kołodziej, Kołodziej-Durnaś 2012), agencji prasowej (Czarniawska 2011), szpitala (Sułkowski 2012a), uczelni wyższych (Sułkowski, Seliga, Woźniak 2016) lub wybranych aspektów kultury, na przykład symbolizmu (Kostera 2010). Przy czym $\mathrm{w}$ badaniach tego typu ważna jest charakterystyka kultury w konkretnej organizacji, a nie szukanie definicji czy budowanie typologii. Jednocześnie warto zaznaczyć, że w efekcie otrzymuje się zbiór licznych studiów przypadków kultur organizacyjnych, które pozwalają lepiej rozumieć zjawiska kulturowe zachodzące w organizacji, choć nie stanowią podstawy do uogólnień.

Wśród strategii badawczych należy wymienić również badania realizowane $\mathrm{w}$ ramach procedur mieszanych: w latach 90. XX w. Hampden-Turner i Trompenaars (2002) prowadzili wywiady i ankiety z menadżerami, w latach 80. XX w. Hofstede (2001) $\mathrm{W}$ ramach badań kultur organizacyjnych (nie badań kultur narodowych) prowadził pogłębione wywiady indywidualne z tym przedstawicielem firmy, który miał największą wiedzę na temat kultury (np. z dyrektorem i sekretarką, dozorcą), oraz ankiety z pracownikami (zajmującymi i niezajmującymi stanowiska kierownicze) w ramach badań 10 organizacji duńskich i holenderskich.

\section{Clinical research - badacz jako pomoc w diagnozowaniu i rozwiązywaniu problemów}

\section{Zdefiniowanie clinical research}

Opisując clinical research (CR), Schein nazywa go wprost paradygmatem (1993) i gromadzenie da- 
nych w sytuacji klinicznej uzasadnia zarówno poprzez różnicę wobec tradycyjnego, pozytywistycznego ulokowania badacza wobec badanej rzeczywistości, niezbędną dla poznania kultury, jak i poprzez efektywność. CR zakłada zaangażowanie badanych niezbędne ze względu na fakt, że według Scheina nie można badać systemów społecznych bez dokonywania interwencji $\mathrm{w}$ ich istotę, a tym samym - bez ich zmieniania, co w szczególności dotyczy kultury.

Utrzymanie dystansu postulowane przez tradycyjne podejścia badawcze nie jest więc $\mathrm{w}$ badaniach kultury możliwe. Co więcej - kliniczność badania, związana z faktem, że aranżuje ją sama organizacja (jej przedstawiciele) w sytuacji, w której poszukuje pomocy, prowadzi do większego zaangażowania członków organizacji i otwiera ją na interwencję (niezbędną do poznania kultury), co pozwala badaczowi na głębsze rozpoznanie: procedur obronnych działających $\mathrm{w}$ organizacji, ukrytych założeń sterujących zachowaniami, relacji interpersonalnych i grupowych oraz władzy i autorytetów. Budowanie pomocowej, wspierającej relacji (psycholog nazwałby to sojuszem terapeutycznym) opiera się na uzyskiwaniu przez samą organizację pełniejszej wiedzy o sobie i zrozumienia (Schein 1993: 14).

Schein podkreśla, że podejścia klinicznego nie można utożsamiać ani z badaniem jakościowym, ani z etnografią organizacji (1993), ani nawet $z$ tak zwanym action research (1995), w którym inicjatorem badania jest organizacja. Podstawą odrębności jest odrzucenie typowego dla paradygmatu pozytywistycznego ulokowania badacza poza badaną sytuacją, jako zewnętrznego obserwatora. Tymczasem CR wypływa z potrzeby zmiany i interwencja stanowi w nim kluczowy aspekt tak poznania organizacji, jak i rozwiązania jej problemu. Co więcej, Schein jednoznacznie odrzuca wykorzystywanie wszelkich kwestionariuszy: skoro każde gromadzenie danych jest interwencją, to problemem badań standaryzowanych jest z jednej strony narzucanie badanym pojęć i perspektywy twórcy narzędzia, niezależnie od tego, czy są, czy też nie są w jakikolwiek sposób odpowiednie, z drugiej zaś nieświadomość rzeczywistych konsekwencji. W efekcie takie badanie jest interwencją (np. w postawy, myślenie o sobie i organizacji), której kierunku i głębokości badacz nie zna (Schein 1993: 16; 1995).

Badanie realizowane $\mathrm{w}$ ramach $\mathrm{CR}$ jest $\mathrm{w}$ istocie częścią procesu pomocowego - analogicznie jak diagnoza w psychologicznej relacji wsparcia jednostki - poprzez samą nawiązaną relację i poprzez umożliwienie urefleksyjnienia i zwerbalizowania doświadczeń, ukrytych zasad i sposobów działania, stanowiących dla organizacji problem. CR pozwala podjąć poszukiwanie rozwiązań (albo poprzez zmianę elementów kultury, albo poprzez wypracowanie procedur z nią zgodnych). Pomocowy charakter CR jest istotny także dla motywacji i zaangażowania w badanie członków organizacji - ponieważ na pierwszym miejscu ulokowane są interesy/potrzeby organizacji i badani jej członkowie są tego świadomi, są też zmotywowani i zaangażowani we współpracę z badaczem, co jest przeciwieństwem sytuacji, w której to badacz potrzebuje informacji, a ich uzyskanie zależy od dobrej woli członków organizacji, którzy w udzielaniu ich nie dostrzegają żadnego własnego interesu. Schein wskazuje, że $\mathrm{w}$ ten sposób kontrakt psychologiczny zmienia się radykalnie, dając potencjalnie badaczowi dostęp do znacznie bardziej zaangażowanych badanych (co jak zastrzega - nie prowadzi automatycznie do głębszych czy trafniejszych wyników) (Schein 1993). 


\section{Opis procedury według wskazań Scheina}

CR może być podejściem zastosowanym do badania wszelkich aspektów działalności organizacji, jednak jego zastosowanie do badania kultury organizacyjnej wydaje się przypadkiem szczególnie obrazowo ukazującym korzyści i ograniczenia procedury. Opisując szczegółowo sposób badania kultury organizacyjnej zgodnie $\mathrm{z}$ procedurą $\mathrm{CR}$, Schein (1993) omawia szereg etapów, przy czym zaznacza, że punkt wyjścia stanowi problem organizacji, która zwraca się do badacza o pomoc. Badanie realizowane jest w grupie liczącej od 5 do 100 osób i obejmuje:

1. uznanie grupy chcącej rozwiązać problem za grupę, która chce nauczyć się analizować własną kulturę (kulturę własnej organizacji);

2. przedstawienie grupie założeń i pojęć podstawowych dla koncepcji kultury Scheina (autor przewiduje na ten etap około 30 minut);

3. spisanie przez grupę artefaktów własnej kultury - zdaniem Scheina istotne jest rozpoczęcie od najbardziej namacalnych i konkretnych składowych kultury, spisy służą dalszej pracy, a Schein wskazuje, że byłoby dobrze, gdyby pracę i wskazywanie artefaktów rozpoczynały osoby o najkrótszym stażu w organizacji. Listy artefaktów umieszcza się na ścianach lub stojakach, spisane na przykład na dużych kartach - ich widoczność ma prowokować dyskusję i uzupełnienia oraz prowadzić do kolejnego etapu;

4. przejście do dyskusji o wartościach i ukrytych założeniach. Schein wskazuje, że zwykle dokonuje się spontanicznie. Praca $\mathrm{w}$ grupach związana $\mathrm{z}$ dyskusją o wartościach, przykładach i wyjaśnieniach zachowań jest kluczowa dla wzajemnej stymulacji, refleksji i werbalizacji wartości i ukrytych założeń, ponieważ znaczna część kultury ma nieświadomy charakter i niezbędne jest ich zwerbalizowanie. Zadaniem badacza jest wyłonienie z dyskusji aspektów najważniejszych (z perspektywy rozwiązania problemu) i kierowanie na nie uwagi uczestników;

5. przejście do rozważania na temat konsekwencji, to jest wskazania, jak wartości i założenia sprzyjają różnym rodzajom aktywności w organizacji (lub je utrudniają). Ten etap obejmuje też przełożenie tych rozważań na rozwiązanie zgłaszanego problemu.

Schein wskazuje na efektywność badania kultury organizacyjnej wskazaną metodą - proces prowadzi nie tylko do znalezienia rozwiązania dla problemu, który zgłosiła organizacja, ale także do szybkiego uzyskania przez badacza wiedzy na temat kultury organizacyjnej i to od razu na poziomie ukrytych założeń. Ograniczeniem procedury jest niewątpliwie fakt, że obraz kultury organizacyjnej nie jest kompletny, ale autor zauważa, że pozwala poznać dynamikę kultury w sposób, który nie jest osiągalny przy zastosowaniu kwestionariuszy, wywiadów czy obserwacji. Uzyskany obraz kultury organizacyjnej jest przy tym trafny, co wynika ze stosowania procedury ciągłego stawiania i poddawania weryfikacji kolejnych hipotez jej dotyczących (nieustanna [re]konceptualizacja) - obok utrzymywania i ukierunkowywania aktywności uczestników jest to najważniejsze zadanie badacza.

\section{Konsekwencje podejścia i wytycznych Scheina}

Schein w definicji kultury podkreśla to, co wspólne (podzielane) przez członków grupy. Celowo pod- 
kreśla w swojej koncepcji stabilne elementy kultury, nazywając je szkieletem kultury, który zmienia się powoli. $W$ procesie powstawania i trwania kultury istotne jest osiągnięcie konsensusu. Ta koncepcja należy do zbioru koncepcji badających kultury dominujące w organizacji i zgodna jest ze starym rozumieniem kultury (old meanings of culture; old ideas of culture). Według Susan Wright stare koncepcje kultury definiowały ją przez odniesienie do pewnego, zamkniętego zbioru, którego członkowie traktowani są jako identyczne, homogeniczne jednostki, przez wyróżnianie stałych cechy (checklist), niezmienność, czyli trwanie w pewnej równowadze lub samoreprodukcji, u podstaw której leżą podzielane znaczenia, tak zwana kultura autentyczna (na którą składają się specyficzne dominujące ideologie lub autorytatywne dyskursy, które nie były ani ponadczasowe, ani równomiernie udostępniane) (Wright 1998: 8). Takie podejście do kultury jest krytykowane za wspieranie dominującej kultury w danej grupie, przy jednoczesnym ignorowaniu mniejszości. „Przenosząc krytykę starych koncepcji kultury na pole badań organizacji, należałoby zwrócić uwagę na fakt, że znaczna większość opisów kultury organizacyjnej, czyli opisów analiz następujących po zdefiniowaniu pojęcia «kultura organizacyjna», jest właśnie zamykaniem organizacji i tworzacych je ludzi w kulturowych kapsułach. Etyczne i metodologiczne efekty takiego podejścia są podobne do tych znanych z antropologii: 1) wzmacnianie hegemonii dyskursu dominującego; 2) spójna wizja całości kosztem utraty zrozumienia złożoności" (Krzyworzeka 2012: 76). Przy czym wydaje się, że dążenie do wykreowania i utrzymania kultury podzielanej przez większość jest istotnym celem organizacji, a istnienie wielu subkultur (Schein nazywa taką organizację systemem wielkokulturowym) postrzegane bywa jako źródło konfliktów i napięć.
„W organizacjach często istnieje wiele różnych i rywalizujących ze sobą systemów wartości, które tworzą raczej mozaikę realiów organizacji niż jednolitą kulturę. (...) Interesujące jest, że osiągające sukcesy organizacje obserwowane przez T. Petersa i R. Watermana, jak się wydaje, znalazły sposoby przełamania tych podziałów funkcjonalnych tak, że przedstawiciele różnych zawodów potrafią kierować swoimi działaniami, odwołując się do wspólnego i zintegrowanego zestawu norm i priorytetów. Jednak w wielu organizacjach podziały są nad wyraz realne, czego wynikiem jest powstanie zestawu zawodowych subkultur, które komunikują się ze sobą z najwyższą trudnością" (Morgan 1999: 144). Można postawić pytanie, czy badaczom kultur organizacyjnych i samym organizacjom zależy na zerwaniu z koncepcją kultury dominującej, gdy wciąż utożsamia się sukces organizacji z silną kulturą organizacyjną (rozumianą także jako spójna, wspólna).

Jak pisze Wright, nawet ci badacze, którzy ujmują organizację jako kulturę (np. Smircich 1985; Schein 1991), przesuwają definicję od nowego znaczenia kultury jako ciągłego procesu tworzenia znaczeń do starego, w którym kultura jest traktowana jako pewna rzecz, którą można wytworzyć, narzucić i kontrolować (Wright 1998: 12).

CR Scheina jako podejście badawcze wyrasta $\mathrm{z}$ takiego właśnie rozumienia kultury i w ten sposób - mimo rozbudowanej partycypacyjności, zaufania względem refleksyjności badanych i otwartości interpretacyjnej - pozostaje zamknięte na fakt, że być może owym zgłaszanym problemem organizacji są nie tyle niespójności jej kultury, co nieadekwatność pomiędzy (starą) kulturą a (nową, sieciową) strukturą. Można jednak sądzić, że powszechność organizacji, w których zarządzający opierają się 
na starym rozumieniu kultury i które zachowują tradycyjną (raczej biurokratyczną niż organiczną) strukturę, pozostawia znaczne pole dla podejścia CR. Tym bardziej, że z jednej strony dzięki zbieżnościom z założeniami innych procedur badawczych nauk społecznych i humanistycznych może się wraz z nimi rozwijać, zaś z drugiej - same konstytutywne cechy CR umożliwiają badaczom (jeśli się tego podejmą) przekierowanie uwagi (odnotowanie, interpretację) na niedominujące, niszowe czy subkulturowe aspekty kultur badanych organizacji.

\section{Dyskusja}

Rozważania nad podobieństwem CR do wybranych podejść badawczych charakterystycznych dla psychologii, socjologii i antropologii prowadzone są poprzez takie kategorie opisujące podejście badawcze jak: 1) relacje badacz-badany, 2) przyjmowana perspektywa badania kultury, w szczególności badania partycypacyjne i zaangażowanie badanych, 3) sposób gromadzenia danych, praca z pojęciami, sposób weryfikacji hipotez, 4) cel badań. Przedstawiona dyskusja ukierunkowana jest na poszukiwanie zbieżności pomiędzy wybranymi procedurami badawczymi, w tym założeniami badań psychologicznych, socjologicznych i antropologicznych, z jednoczesnym przedstawieniem ich podstawowych charakterystyk.

\section{Kliniczność clinical research - założenia diagnozy psychologicznej a wytyczne Scheina}

Zbieżność założeń i realizacji CR z podejściem psychologii praktycznej, to jest diagnozy i pomocy psychologicznej, to główny obszar odpowiadający za „kliniczność” koncepcji Scheina. Chociaż nie wskazuje on na to wprost, analogiczne do psychologii podłoże ma samo nawiązanie relacji z badaczem, które wynika z potrzeby organizacji - podobnie zatem jak w przypadku wsparcia psychologicznego punkt wyjścia stanowi oczekiwanie wsparcia, z jakim zjawia się klient. W przypadku organizacji sytuacja jest o tyle bardziej złożona, że po pomoc zgłasza się przedstawiciel wieloosobowego podmiotu, zaś diagnozy i pomocy wymagają nie tylko (a nawet nie przede wszystkim) członkowie organizacji, ale dynamiczne relacje, jakie między nimi zachodzą.

Drugi istotny punkt zbieżności stanowi przekonanie Scheina, że każdy kontakt, każdy sposób gromadzenia danych jest interwencją, to znaczy działaniem, które wprowadza zmianę. Zwrócenie na to uwagi służy nie tylko wskazaniu, z jak wielką ostrożnością należałoby (jeśli w ogóle) stosować wszelkie narzędzia badawcze (szczególnie standaryzowane), ale i uświadomieniu, że rozpoczynając diagnozę, rozpoczyna się jednocześnie terapię. Analogiczne wytyczne formułują psycholodzy. Nieunikniony splot diagnozy i interwencji ujawnia się chociażby $\mathrm{w}$ rozważaniach etycznych psychologów i wskazywaniu na znaczenie ustalanego zawsze w pierwszej kolejności kontraktu pomiędzy psychologiem a klientem - jak podkreśla Toeplitz-Winiewska, „po pierwsze należy ustalić cel badania i ewentualne konsekwencje tego badania dla danej osoby" (2002: 825). Kontrakt obejmuje przede wszystkim ustalenie: celu działania psychologa, zakresu jego interwencji, oczekiwanych przez klienta skutków, czasu trwania usługi i wynagrodzenia. Te wytyczne mają między innymi zapobiegać niefrasobliwemu nadużywaniu narzędzi badawczych czy folgowaniu ciekawości psychologa. Ostrożność związana jest z nierównością, jaka charakteryzuje relację psycholog-klient, zaś w przypadku organizacji staje się jeszcze bardziej złożona, ponieważ obejmuje ograniczony zakres odmowy poddania 
się badaniu przez podwładnych, gdy zleca je przełożony. Jednocześnie poprzez wymuszanie pewnej refleksji każde gromadzenie danych jest interwencją, jest nią nawet pozornie nieuczestnicząca obserwacja (co w naukach o organizacji zwykle rozpatrywane jest pod pojęciem efektu Hawthorne, w psychologii społecznej wiąże się z efektem facylitacji, a w etnografii prowokuje do pytań o faktyczne nieuczestniczenie).

Trzecim aspektem CR, który zbliża to podejście do diagnozy psychologicznej, jest kwestia zaangażowania. Podobnie jak psycholog, diagnozując i wspierając klienta, opiera się przede wszystkim na jego motywacji (nawet jeśli zleceniodawcą diagnozy jest instytucja, niezbędna jest zgoda badanego, któremu przedstawiono sens i zakres badania, który zrozumiał jego konsekwencje i przynajmniej w tym minimalnym zakresie jest $\mathrm{w}$ badanie zaangażowany, tj. zmotywowany), tak badacz wkraczający do organizacji na jej prośbę może, zdaniem Scheina, liczyć na nieporównanie większe zaangażowanie członków organizacji, którzy świadomi są potrzeby czy problemu organizacji i w imię lojalności wobec niej (a przynajmniej wspólnych interesów) angażują się w badanie. Innymi słowy - członkowie organizacji mają interes we współpracy z badaczem, podobnie jak klient zainteresowany jest współpracą z psychologiem.

Powyższe punkty, które wprowadzają wątki rozważane przez psychologów w ramach dyskusji nad etyką pracy, wprowadzają czwarty istotny punkt zbieżności związany z odpowiedzialnością badacza - skoro celem CR jest diagnoza i interwencja, to wiąże się ona $z$ dokonywaniem istotnej zmiany w organizacji, to zaś oznacza, że badacz nie może ograniczyć swojej odpowiedzialności do przedstawienia możliwie rzetelnego raportu. Psycholog działa przede wszystkim dla dobra swojego klienta, zgodnie ze zdefiniowanym w ramach kontraktu celem (szczegółowym lub ogólnym), co określa zakres interwencji. Analogicznie powinien postępować badacz w organizacji, chociaż w tym przypadku dynamika i siła wpływu są odmienne, to znaczy badacz uruchamia pewne procesy, a ich przebieg i konsekwencje leżą po stronie organizacji. Ta różnica wynika z odmiennej niż w przypadku relacji psychologicznej siły wpływu - badacz jako ekspert jest wobec organizacji na słabszej pozycji niż psycholog wobec klienta. Wskazanie Scheina, że grupę reprezentującą organizację traktuje on przede wszystkim jak grupę ludzi, którzy chcą się nauczyć, jak badać własną kulturę organizacyjną, oddaje tę różnicę i zakres odpowiedzialności badacza, która wiąże się przede wszystkim z przekazaniem samej organizacji niezbędnych jej do rozwiązania problemu narzędzi.

I wreszcie należy wskazać na bardzo istotny element CR związany z aktywnością poznawczą badacza jest to wymóg stawiania i weryfikowania kolejnych hipotez, w psychologii określany mianem konceptualizacji przypadku lub opracowaniem przypadku (por. Słysz 2017). Schein wskazuje, że zadaniem badacza jest nieustanne weryfikowanie stawianych hipotez i tworzenie nowych na podstawie uzyskiwanych informacji. Analogiczne zadanie stawiane jest przed psychologiem. „Konceptualizacja jako proces jest to intencjonalna aktywność psychologa, ukierunkowana na to, by zrozumieć przypadek danego klienta - jego różne aspekty i uwarunkowania oraz mechanizmy psychologiczne odpowiedzialne za obecny stan rzeczy" (Stemplewska-Żakowicz 2009: 178), co wymaga łączenia teorii z praktyką, dobrej wiedzy o narzędziach czy nieprzywiązywania się do roboczych hipotez, ale poddawania ich weryfikacji i formułowania nowych po ich odrzuceniu. 
Szczegółowe wytyczne dotyczące prowadzenia konceptualizacji różnią się w różnych podejściach psychoterapeutycznych (Stemplewska-Żakowicz 2009; Słysz 2017). Analogicznie w przypadku CR badacz, wzbogacając swoją wiedzę o organizacji (w szczególności jej dynamicznie ujmowanej kulturze), tworzy kolejne hipotezy i poddaje je weryfikacji, na przykład zwracając na nie uwagę uczestników badania i prowokując ich do dyskusji nad nimi. W bardziej rozbudowanych schematach badania weryfikacją są wprowadzane w organizacji zmiany i ich efektywność (jej brak wskazuje na nietrafność). Konceptualizacja jako proces jest zatem tym, co wyznacza przebieg procesu diagnostycznego (np. zastosowanie kolejnych narzędzi, przywoływanie określonych treści w pytaniach, sposób ich formułowania). Psychologowie dużo bardziej szczegółowo niż Schein w odniesieniu do CR opisują i rozważają w różnych ujęciach składowe konceptualizacji (por. Słysz 2017).

\section{Socjologiczność clinical research - trop interwencji socjologicznej i dialogiczność}

Socjologiczność podejścia Scheina widać przede wszystkim w metodologii i sposobie prowadzenia badań, w których nacisk został położony na pogłębione zrozumienie badanego zjawiska, ciągłe tworzenie i weryfikowanie hipotez w dialogu, wspólne uzgadnianie znaczeń, zaangażowanie uczestników i włączenie ich w proces badawczy, wspólne poszukiwanie rozwiązania problemów i dążenie do osiągnięcia akceptacji dla zmiany. To z kolei kieruje uwagę ku jakościowym strategiom i metodom badawczym w socjologii, takim jak interwencja socjologiczna, badania z użyciem pojęć uwrażliwiających czy metody fenomenologiczne.

Metoda interwencji socjologicznej A. Touraine'a bada zachowania zbiorowe $\mathrm{z}$ bliska i bezpośrednio, czyli wchodzi w kontakt z aktorami społecznymi, którzy wraz z socjologami są równoprawnymi uczestnikami i autorami badań. Badanie to opiera się na autoanalizie działań i oryginalnie dedykowane jest badaniu ruchów społecznych. Schein, wchodząc do organizacji, oddaje głos jej członkom, natomiast badacz moderuje i animuje dyskusję. Podobnie u Touraine'a - badacz jest zdystansowanym obserwatorem, ewentualnie mediatorem. Animuje dyskusję: zachęca, ukierunkowuje, stawia hipotezy i je weryfikuje. Jak zauważa Matuchniak-Krasuska (1995: 101), ,interwencja nie izoluje badanego aktora społecznego z jego naturalnego środowiska i działania. Ujmuje aktora społecznego w interakcji z jego partnerami społecznymi".

Praca odbywa się $\mathrm{w}$ grupach. Badani dysponują znaczną swobodą wypowiedzi, mogą ją uszczegóławiać, dodawać, zmieniać, interpretować czy wyjaśniać. Pojawia się zatem efekt grupowej stymulacji, która wpływa na poziom zaangażowania badanych. Touraine spotkania z badanymi nazywa seansami, mają one charakter spotkań otwartych (z zaproszonymi gośćmi) i zamkniętych (z udziałem tylko członków badanej grupy). Pierwszy seans ma na celu poznanie się uczestników i badaczy, ale także swobodne wyłonienie tematów, które są istotne z punktu widzenia badania. Seanse otwarte umożliwiają uzupełnienie wiedzy, poznanie punktów widzenia, ujawnienie założeń poprzez dyskusję z autorytetami lub przeciwnikami ruchu. Seanse zamknięte przeznaczone są na autoanalizę, która „dokonywana przez grupę przy pomocy badaczy pozwala na coraz lepsze zrozumienie własnego ruchu społecznego (w naszym przypadku kultury organizacyjnej - przyp. AB, AJ), swojej roli, tożsamości, planów. Uczestnik ruchu podejmuje refleksję nad własnym działaniem, dystansuje się wobec niego. Przebiega to etapami czy raczej krok po kro- 
ku i bywa kwitowane przez uczestników: «Eureka» («ach, rozumiem», «to dlatego»). Każdy postęp $\mathrm{w}$ tym kierunku nosi nazwę fleksji - zmiany (flexion). Momentem przełomowym jest faza konwersji (conversion) polegająca na podjęciu przez badanych roli badaczy analizujących swoje działanie" (Matuchniak-Krasuska 1995: 105).

W obu metodach możliwe jest ponowne badanie, jeśli grupa odczuwa taką potrzebę. Wykreowanie takiej potrzeby jest sukcesem interwencji socjologicznej. Obie metody zakładają długotrwałe przebywanie $\mathrm{w}$ terenie. To $\mathrm{z}$ kolei wiąże się $\mathrm{z}$ ciągłym renegocjowaniem dostępu do tego terenu. Mimo różnicy $\mathrm{w}$ zaproszeniu do badań ( $\mathrm{w} C \mathrm{C}$ to organizacja zaprasza badacza) w obu metodach może się pojawić problem tak zwanych odźwiernych, czyli tych przedstawicieli grupy, o których zgodę i przychylność powinien badacz zabiegać nie tylko na początku, ale i w trakcie prowadzenia długotrwałych badań terenowych (Hammersley, Atkinson 2000: 73-74).

Metoda interwencji socjologicznej angażuje badanych $\mathrm{w}$ proces introspekcji, w którym poprzez analizę tego, jak moga postrzegać i interpretować własne działania i własny świat społeczny, wspomaga ich socjolog. Celem metody jest ukazanie prawdziwych relacji, tak by możliwe było zdefiniowanie wymiarów/poziomów, które strukturalizują działania aktorów w rzeczywistości, w której funkcjonują (Frybes 2019: 72). Zatem metoda ta pozwala uzyskać pogłębioną wiedzę, która jest weryfikowana przez członków organizacji - bez ich akceptacji analiza socjologiczna nie może się zakończyć.

Sposób podejścia do relacji badacz-badany (badacz nie zajmuje dominującej pozycji $\mathrm{w}$ procesie badawczym) w CR charakterystyczny jest również dla me- tody fenomenologicznej w socjologii. W tym podejściu badacz odsuwa od siebie wiedzę teoretyczną i związane $z$ nią sądy wartościujące, dzięki czemu potrafi dostrzec fenomen takim, jakim on jest dla badanych. To pierwszy etap - epoché, czyli postępowanie zgodnie z instrukcją Husserla „brania w nawias" założeń, subiektywnych poglądów w trakcie badania. Drugim etapem postępowania metodologicznego jest redukcja fenomenologiczna - fenomen traktujemy jako niepowtarzalny, jedyny w swoim rodzaju, na który badacz patrzy w świeży i otwarty sposób. Ostatni etap, czyli wyobrażeniowe uzmiennianie, kończy się opisem struktury istoty fenomenu. Efektem jest całościowy opis fenomenu, co jest możliwe poprzez procesy rozumienia i interpretacji (Moustakas 1994: 113-121).

Szukając kolejnych tropów łączących CR i badania socjologiczne, można odwołać się także do pracy z pojęciami. Schein badania metodą $C R$ rozpoczyna od wprowadzenia pojęć, które mają wywołać dyskusję. W trakcie badań badacz stawia hipotezy, weryfikuje je, stawia nowe, dopytuje. Bliskie jest to badaniom z użyciem pojęć uwrażliwiających Herberta Blumera. Pojęcia konstruowane w języku badanych (używamy ich wyrażeń, słownictwa) wyznaczają jedynie kierunek pytań, badacz nie podaje definicji. Pojęcia te kierują zatem uwagę na ważne cechy społecznych interakcji i stanowią przewodnik dla badań w określonym kontekście (Bowen 2006: 3). Według Krzysztofa Koneckiego badanie z wykorzystaniem tych pojęć polegałoby na: „dokładnym opisie badanego zjawiska (tego, jaka jest jego treść i jak dane zjawisko przebiega) (...), a następnie jego interpretacji w związku z kontekstem jego występowania (...) oraz koncentracji na indywidualnym przeżywaniu przez jednostki określonego zjawiska oraz jego społecznego definiowania" (Konecki 2019: 34). Przypisywanie znaczeń, ich komentowanie i wspólne in- 
terpretowanie pozwalają zrozumieć doświadczenia, zjawiska i fakty zachodzące w organizacji. Według Scheina uważane za ważne, za oczywiste w organizacji (np. sposób działania, wartości) jest to, co podlegało społecznej walidacji, czyli zostało potwierdzone przez podzielane społeczne doświadczenia grupy. Badacza interesują nie tyle "obiektywne" zachodzące w organizacji wydarzenia jako fakty, co ich społeczne konstruowanie. Łucewicz (1997: 22) zauważa, że prowadzi to do ujmowania organizacji jako „konfiguracji znaczeń tkwiących w symbolach, mitach, rytuałach, ceremoniach, których nośnikami są uczestniczący w tych organizacjach ludzie". Oczywistym ryzykiem płynącym z tego podejścia są błędne interpretacje, ale też ograniczenie się do ujawnienia (ujęcia w badaniu i przedstawienia) tylko interpretacji dominującej.

\section{Unikatowość przypadku - etnograficzne skupienie $\mathrm{w}$ clinical research}

Koncentracja na przypadku, opisie jego unikatowości to wspólna cecha CR i etnografii. Badane zjawiska ujmowane są w naturalnym kontekście. Obie metody opierają się na względnie długotrwałej obecności w terenie. „Etnografia wyjątkowo dobrze nadaje się do badań podejmowanych $\mathrm{w}$ celu odpowiedzi na pytania badawcze zaczynające się od «dlaczego?» (...). Umożliwia to ukazanie zjawisk społecznych $\mathrm{w}$ ich bogatym kontekście, bez abstrahowania, biorąc pod uwagę tło, przy padki nietypowe, jednostkowe. Takie niespodziewane wydarzenia zmieniające zwykły sposób funkcjonowania organizacji nie są traktowane jako zakłócenia"' (Kostera 2003: 26-27).

W obu metodach istotne jest dopuszczenie do głosu badanych, aby przedstawić badane zjawisko / badany teren $\mathrm{w}$ realistyczny sposób. Jedynie jednostka będąca w danej kulturze może ją zrozumieć, ponieważ to ludzie nadają sens działaniom. Stąd w badaniach często stosowany jest tak zwany gęsty opis (thick description), czyli opis zachowań i ich kontekstu, opis kultury oczami jej uczestnika. To opis i próba zrozumienia znaczeń, jakie uczestnicy przypisują zaobserwowanym fenomenom. Co więcej, obie metody koncentrują się raczej na perspektywie emic (badaniu kultury od strony jej użytkowników, czyli na postrzeganiu i rozumieniu zjawisk w sposób właściwy dla członków kultury/organizacji) niż etic (z pozycji zewnętrznego obserwatora). Badacz, przebywając w terenie, uczy się „wyrzucać do śmieci poprzednie hipotezy i pozwalać, by (...) rozmówcy powiedzieli [mu] o tym, co jest dla nich ważne" (Kostera 2003: 43). Przy czym wypowiedzi badanych „są częścią opisywanego (...) świata, a przez to kontekst, w którym odbywa się proces komunikowania, nadaje im w pewnej mierze kształt" (Hammersley, Atkinson 2000: 133). Istotne jest zatem wnikliwe rozumienie wypowiedzi i jej kontekstu, „,czyli założeń leżących u jej podstaw, osoby będącej autorem, adresata i przyczyny powstania" (Hammersley, Atkinson 2000: 133).

Zarówno w CR, jak i w etnografii koncentracja na przypadku to dążenie do jego dogłębnego poznania i zrozumienia poprzez całościowe spojrzenie na zjawiska, fakty, procesy dziejące się wewnątrz przypadku z uwzględnieniem kontekstu, tak aby przedstawić zgodnie z prawdą doświadczenia ludzi. „Dostarczenie szczegółowego opisu pewnych praktyk w obrębie przypadku opiera się na co najmniej milczącym założeniu, że opisane praktyki są typowe dla całego przypadku lub dla pewnych jego aspektów - to znaczy, że nie są tylko arbitralnie wybranymi zdarzeniami" (Flick 2010: 158). Wiedza zdobyta $w$ trakcie badania etnograficznego jest holistyczna, to znaczy badacz dostrzega badany świat społeczny w całej złożoności i w szerszym kontek- 
ście. Elementem łączącym CR i etnografię jest też cel praktyczny obu metod, czyli pomoc w rozwiązywaniu problemów grupy. Etnografia „może zwiększyć zrozumienie dla konkretnych ludzi i ich problemów. (...) może stanowić cenną pomoc w twórczym podejściu do rozwiązywania problemów" (Kostera 2003: 28-29), zaś CR wypływa z potrzeby rozwiązania konkretnych trudności w organizacji.

\section{Zakończenie}

Powszechność przywoływania koncepcji kultury organizacyjnej sformułowanej przez Scheina nie przekłada się na omówienie czy wykorzystanie zaproponowanej przez niego procedury badań. Tymczasem procedura ta, ze względu na swój bardzo precyzyjny opis i ściśle praktyczny (z perspektywy organizacji) charakter, wydaje się gotowa do zastosowania, wdrożenia w praktyce na przykład audytów. Ma też ogromny potencjał upodmiotawiający uczestników badania, czego nie ma w większości stosowanych metod badania kultury organizacyjnej. Prowadzi przez to nie tylko do uzyskania wiedzy na temat sytuacji w organizacji i do znalezienia rozwiązania jej problemów, ale i daje efekty związane ze zwiększaniem zaangażowania pra-

\section{Bibliografia}

Alvesson Mats (2002) Understanding Organizational Culture. London: Sage Publications Ltd.

Bowen Glenn (2006) Grounded Theory and Sensitizing Concepts. „International Journal of Qualitative Methods", nr 5(3) [dostęp 12 grudnia 2019 r.]. Dostępny w Internecie: ‘https://sites.ualberta.ca/ iiqm/backissues/5_3/PDF/bowen.pdf>. cowników. Z perspektywy głównych dyscyplin nauk społecznych unikalną cechą CR jest fakt, że wspólne założenia dzieli z szeregiem procedur badawczych - najobszerniej z diagnozą psychologiczną, ale także z interwencją socjologiczną, podejściem fenomenologicznym i etnografią. Bazuje na odmiennym niż klasyczne, postpozytywistyczne podejście badawcze, będąc bliżej badań realizowanych $\mathrm{w}$ paradygmatach zaangażowania czy konstruktywizmu (Creswell 2013), oddaje kontrolę nad badaniem jego uczestnikom. Pośrednio ujawnia, jak wiele wspólnego mają ze sobą psychologia, socjologia i antropologia - przynajmniej w aspekcie podejść badawczych. CR ma również wady z punktu widzenia badaczy zorientowanych raczej naukowo największą z nich jest konieczność oczekiwania na zgłoszenie zainteresowania badaniem przez organizację. Istotnym zastrzeżeniem jest także pomijanie niedominujących składowych kultury oraz archaiczność samego rozumienia kultury organizacyjnej przez Scheina (trzeba jednak pamiętać, że podejście to ma już swój wiek), która przyczynia się do pewnej nieadekwatności jego podejścia w kontekście takich cech współczesnych organizacji jak ich wielokulturowość i sieciowa struktura.
Cameron Kim, Quinn Robert (2006) Kultura organizacyjna - diagnoza i zmiana. Przełożyła Bogumiła Nawrot. Kraków: Oficyna Ekonomiczna.

Creswell John W. (2013) Projektowanie badań naukowych. Metody jakościowe, ilościowe i mieszane. Przełożyła Joanna Gilewicz. Kraków: Wydawnictwo Uniwersytetu Jagiellońskiego. 
Czarniawska Barbara (2011) Antropologia i teoria organizacji: wczoraj i dziś. „Problemy Zarządzania”, nr 9(2), s. 11-29.

Czarniawska-Joerges Barbara (1992) Exploring complex organizations: a cultural perspective. Newbury Park, CA: Sage Publications.

Czerska Małgorzata (2012) Uwarunkowania kulturowe zachowań w organizacji [w:] Ryszard Rutka, Piotr Wróbel, red., Organizacja zachowań zespołowych. Warszawa: Polskie Wydawnictwo Ekonomiczne, s. 214-264.

Czerska Małgorzata, Szpitter Agnieszka, red. (2010) Koncepcje zarzadzania: podręcznik akademicki. Warszawa: Wydawnictwo $\mathrm{CH}$ Beck.

Deal Terrance, Kennedy Allan (2000), Corporate culture. The rites and the rituals for corporate life. New York: Basic Books.

Denison Daniel R. (1996) What is the difference between organizational culture and organizational climate? A native's point of view on a decade of paradigm wars. "Academy of Management Review", vol. 21, no. 3, s. 619-654.

Flick Uwe (2010) Projektowanie badania jakościowego. Przełożył Paweł Tomanek. Warszawa: PWN.

Frybes Marcin (2019) Sociological Intervention «a la polonaise»: Alain Touraine's Method in the Polish Context. „Przegląd Socjologii Jakościowej", t. 5, nr 3, s. 70-90.

Hammersley Martyn, Atkinson Paul, Metody badań terenowych. Przełożył Sławomir Dymczyk. Poznań. Zysk i S-ka.

Hampden-Turner Charles, Trompenaars Fons (2002) Siedem wymiarów kultury. Znaczenie różnic kulturowych w działalności gospodarczej. Przełożyła Bogumiła Nawrot. Kraków: Oficyna Ekonomiczna.

Handy Charles (1983) Understanding organizations. New York: Oxford University Press.

Harrison Roger (1972) Understanding Your Organization's Character, „Harvard Business Review”, May-June, s. 119-129.

Hofstede Geert (2001) Kultury i organizacje. Zaprogramowanie umysłu. Przełożyła Małgorzata Durska. Warszawa: Polskie Wydawnictwo Ekonomiczne.

Kmiotek Krystyna, Piecuch Teresa (2012) Zachowania organizacyjne: teoria i przykłady. Warszawa: Difin.
Kołodziej-Durnaś Agnieszka, red. (2005) Terenowe badania kultury organizacji: studia wybranych firm $i$ instytucji. Szczecin: Economicus.

Kołodziej Arkadiusz, Kołodziej-Durnaś Agnieszka (2012) Zarządzanie załoga na statku -badania jakościowe wśród marynarzy. „Zarządzanie Zasobami Ludzkimi” nr 6(89), s. 53-71.

Konecki Krzysztof (1994) Kultura organizacyjna japońskich przedsiębiorstw - studium socjologiczne. Łódź: Wydawnictwo Uniwersytetu Łódzkiego.

Konecki Krzysztof (2007) Nowi pracownicy a kultura organizacyjna przedsiębiorstwa. „Przegląd Socjologii Jakościowej”, t. 3, nr 1, s. $3-126$.

Konecki Krzysztof (2019) Kreatywność w badaniach jakościowych. Pomiędzy procedurami a intuicją. „Przegląd Socjologii Jakościowej", t. 15, nr 3, s. 30-54.

Kostera Monika (1996) Postmodernizm w zarządzaniu. Warszawa: PWN.

Kostera Monika (2003) Antropologia organizacji. Metodologia badań terenowych. Warszawa: Wydawnictwo Naukowe PWN.

Kostera Monika (2007) Kultura organizacji - badania etnograficzne polskich firm. Gdańsk: GWP

Kostera Monika (2010) Organizacje i archetypy. Warszawa: Wolters Kluwer Polska.

Kostera Monika, Śliwa Martyna (2012) Zarządzanie w XXI wieku: jakość, twórczość, kultura. Warszawa: Wolters Kluwer.

Kożusznik Barbara (2014) Zachowania człowieka w organizacji. Warszawa: PWE.

Krzyworzeka Paweł (2012) Kultura organizacyjna - ślepa uliczka teorii organizacji. „Management and Business Administration. Central Europe", t. 1/2012 (108), s. 72-81.

Łucewicz Janina (1997) Socjologiczne spojrzenie na organizację. Wrocław: Wydawnictwo Akademii Ekonomicznej.

Matuchniak-Krasuska Anna (1995) Interwencja socjologiczna A. Touraine'a. Uwagi uczestnika. "Studia Socjologiczne” nr 138-139(3-4), s. 97-108.

Morgan Gareth (1999) Obrazy organizacji. Przełożyła Zofia Wiankowska-Ładyka. Warszawa: PWN. 
Moustakas Clark (1994) Phenomenological research methods. London: Sage Publications.

Okręglicka Małgorzata (2019) Orientacja przedsiębiorcza a kultura organizacyjna w małym przedsiębiorstwie. Częstochowa: Wydawnictwo Politechniki Częstochowskiej.

Robbins Stephen P., Judge Timothy A. (2012) Zachowania w organizacji. Przełożył Andrzej Ehrlich. Warszawa: Polskie Wydawnictwo Ekonomiczne.

Schein Edgar (1980) Organizational psychology. Englewood Cliffs N.J.: Prentice-Hall.

Schein Edgar (1993) Legitimating Clinical Research in the Study of Organizational Culture. „Journal of Consueling \& Development", vol. 71, s. 703-708.

Schein Edgar (1995) Process Consultation, Action Research, and Clinical Inquiry: Are They the Same? Working Paper 3833 [dostęp 15 listopada 2019 r.]. Dostępny w Internecie: ‘http://citeseerx.ist. psu.edu/viewdoc/download?doi=10.1.1.470.451\&rep=rep1\&type=pdf $>$.

Schein Edgar (2010) Organizational Culture and Leadership. San Fransisco: Jossey-Bass. A Wiley Imprint

Schein Edgar (2015) Some thoughts about the uses and misuses of the concept of culture. "Journal of Business Antrophology", vol. 4, no. 1 , s. 106-113.

Sikorski Czesław (2009) Nauka o zarzadzaniu. Łódź: Wydawnictwo Akademii Humanistyczno-Ekonomicznej.

Słysz Anna (2017) Konceptualizacja przypadku w różnych modelach psychoterapii. Poznań: Wydawnictwo Naukowe Wydziału Nauk Społecznych UAM.
Srokowski Łukasz (2011) Zmienić myślenie o firmie: Zarzadzanie kultura organizacyjna w Polsce. Warszawa: Poltext.

Stemplewska-Żakowicz Katarzyna (2009) Diagnoza psychologiczna. Gdańsk: Gdańskie Wydawnictwo Psychologiczne.

Sułkowski Łukasz (2002) Kulturowa zmienność organizacji. Warszawa: Polskie Wydawnictwo Ekonomiczne.

Sułkowski Łukasz (2008) Czy warto zajmować się kultura organizacyjnq? „Zarządzanie zasobami ludzkimi”, nr 6, s. 9-25.

Sułkowski Łukasz (2012a) Cechy kultur organizacyjnych polskich szpitali. Zeszyty Naukowe Wyższej Szkoły Bankowej we Wrocławiu "Zarządzanie zasobami ludzkimi w teorii i praktyce", nr 30, s. 251-260.

Sułkowski Łukasz (2012b) Kulturowe procesy zarzadzania. Warszawa: Difin.

Sułkowski Łukasz (2014) Zmiana kultury organizacyjnej - paradygmaty, modele i metody zarzadzania [w:] Łukasz Sułkowski, Czesław Sikorski, red., Metody zarzadzania kultura organizacyjna. Warszawa: Difin, s. 11-26.

Sułkowski Łukasz, Seliga Robert, Woźniak Andrzej (2016) Rezultaty badań kultur jakości uczelni wyższych w Polsce. „Przedsiębiorczość i Zarządzanie", t. 17, z. 7, s. 75-90.

Toeplitz-Winiewska Małgorzata (2002) Problemy etyczne diagnostyki psychologicznej [w:] Jan Strelau, red., Psychologia. Podręcznik akademicki. Tom 3. Jednostka w społeczeństwie i elementy psychologii stosowanej. Gdańsk: Gdańskie Wydawnictwo Psychologiczne, s. $824-828$.

Wright Susan (1998) The politization of "culture”. „Anthropology Today", vol. 14(1), s. 7-15.

\section{Cytowanie}

Jeran Agnieszka, Basińska Anita (2020) Clinical research Edgara H. Scheina - badanie kultury organizacyjnej między metodyka psychologii, socjologii i antropologii. „Przegląd Socjologii Jakościowej”, t. 16, nr 3, s. 102-119 [dostęp dzień, miesiąc, rok]. Dostępny w Internecie: 〈www.przegladsocjologiijakosciowej.org〉. DOI: http://dx.doi.org/10.18778/1733-8069.16.3.07 


\title{
Edgar H. Schein's Clinical Research: A study on Organizational Culture Between the Methodology of Psychology, Sociology, and Anthropology
}

\begin{abstract}
Edgar H Schein`s approach is one of the most commonly quoted concepts of organizational culture. In it, he recognized organizational culture functionally, interpretatively, and dynamically, pointing to its complexity and multi-levelness. Schein also presented an original method of studying organizational culture, one called clinical research (CR). The authors of this paper discuss the clinical research method and indicate the scope of methodological solutions shared between CR and psychological diagnosis, sociological intervention, and ethnography. The search for support (from the researcher) and the requirement to involve members of the organization are the elements linking CR with psychological diagnosis. As is the case with the sociological intervention of Alain Touraine, CR uses own concepts of the subjects based on their reflectiveness and acceptance of the key findings. And, finally, similarly to ethnography, CR treats each organization as a separate case and sensitizes researchers to permanently build a relationship with their respondents. Therefore, among organizational research procedures, using CR for organizational culture research is a unique example of integrating research methods from within social sciences and the humanities.
\end{abstract}

Keywords: organization research, clinical research, organizational culture, E. H. Schein 